\title{
Fission Product Distribution in Irradiated TRISO Fuel
}

\author{
Karen E. Wright ${ }^{1}$ and Isabella J. van Rooyen ${ }^{2}$ \\ ${ }^{1}$ Karen E. Wright, Idaho National Laboratory, Advanced Characterization Dept., Idaho Falls, ID USA \\ ${ }^{2}$ Isabella J. van Rooyen, Idaho National Laboratory, Fuel Design and Development Dept., Idaho Falls, \\ ID USA
}

Tristructural isotropic (TRISO) fuel particles are designed for use as fuel in high temperature gas reactors. The AGR-1 concentrically layered design consisted of a $350 \mu \mathrm{m}$ diameter, $19.7 \%$ enrichment uranium oxide-carbide fuel kernel in the center, surrounded by layers of a porous carbon buffer layer $(100 \mu \mathrm{m})$, a denser inner pyrolytic carbon layer (IPyC) $(40 \mu \mathrm{m})$, a SiC layer $(35 \mu \mathrm{m})$, and an outer pyrolytic carbon layer $(\mathrm{OPyC})(40 \mu \mathrm{m})$ (Figure 1) [1]. The TRISO design is intended to keep fission products retained within the particle.

In the United States, the main analytical instruments used to study fission product distribution in irradiated fuels include scanning electron microscopy (SEM), transmission electron microscopy, scanning transmission electron microscopy, and high resolution transmission electron microscopy (HRTEM) with corresponding energy dispersive spectroscopy (EDS) [2-4]. While SEM analysis is rapid, and peak resolution is improved with newer silicon drifted detectors, electron probe microanalysis (EPMA) peak resolution remains superior, and is essential to the quantitative analysis of nuclear fuels. Moreover, techniques such as HRTEM-EDS provide chemical analysis of small (e.g. 10-1000nm) areas while EPMA can provide chemical analysis of larger regions $(>1 \mu \mathrm{m})$. With the installation of a shielded EPMA at Idaho National Laboratory, quantitative analysis of irradiated fuels by EPMA is now possible in the United States. The analysis of particle AGR-1-523-SP01 shows our initial investigation into the use of EPMA for irradiated nuclear fuel analysis. Compact 5-2-3, from which particle AGR-1523-SP01was obtained, was irradiated for 620 days to a burn-up of $17.4 \%$. The time-average, volumeaverage temperature of the compact was $1059^{\circ} \mathrm{C}$; however portions of the compact achieved peak temperatures of $1438^{\circ} \mathrm{C}$.

The sample was mounted in a metallography mount, and oriented in such a way as to expose a Pdcorroded area of the $\mathrm{SiC}$ layer [5]. It was then polished to expose the cross section at the maximum diameter and was coated with aluminum. Electron probe microanalysis was used to analyze both individual locations and in the construction of quantitative maps. Software employed was Probe for EPMA (for individual spots) and Peak Sight (for quantitative maps).

There appear to be three types of fission product distributions. Plutonium and fission products such as $\mathrm{Sr}$, Te, and rare earth elements such as Ce tend to stay in the kernel, whereas fission products such as $\mathrm{Cs}$, $\mathrm{I}, \mathrm{Ba}$, and $\mathrm{Xe}$ tend to accumulate in the buffer. Finally, fission products such as $\mathrm{Pd}, \mathrm{Cd}$, and $\mathrm{Ag}$ appear to stay largely within the kernel, but in fact migrate along the failure crack in this particle to precipitate along the walls of the crack and along the SiC-IPyC interface. Palladium penetrates approximately 20 $\mu \mathrm{m}$ into the $\mathrm{SiC}$ layer before it becomes undetectable (Figure 2).

Precipitates in the crack are rich in $\mathrm{Pd}, \mathrm{Cd}, \mathrm{Ag}$ and $\mathrm{Sn}$ whereas those along the SiC-IPyC interface contain relatively less $\mathrm{Pd}, \mathrm{Cd}, \mathrm{Ag}$, and $\mathrm{Sn}$ than those in the crack but are enriched in $\mathrm{Cs}, \mathrm{Ba}$, and $\mathrm{Xe}$ (Figure 3). 
Our results are similar to those shown by Barrachin et al. [6], but this is the first use of this capability to examine irradiated TRISO particles in the United States. Future work will focus on: 1) establishing mass balance between the different reservoirs of fission products in the particle, 2) creating matrixmatched standards for $\mathrm{C}$ and $\mathrm{O}$ analysis, and 3) optimizing measurement parameters for the different matrices present in TRISO particles.

References:

[1] P.A. Demkowicz et al., Transactions of the American Nuclear Society, 106, (2012) 1264-7

[2] I.J. van Rooyen et al., Nuclear Engineering and Design 271, (2014), 114-122.

[3] H.M. Wen, et al., Microsc. Microanal. 21, (2015), 747-748.

[4] I.J. van Rooyen, et al., Paper HTR2014-3-1255, HTR 2014 Conference, Weihai, China (2014).

[5] J.D. Hunn, et al., Paper HTR2014-31254, HTR 2014 Conference, Weihai, China (2014).

[6] M. Barrachin et al., Journal of Nuclear Materials, 415, (2011), 104-116.

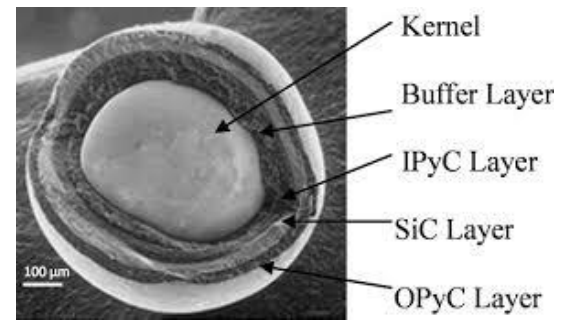

Figure 1. Shows the concentric layered structure of a TRISO particle
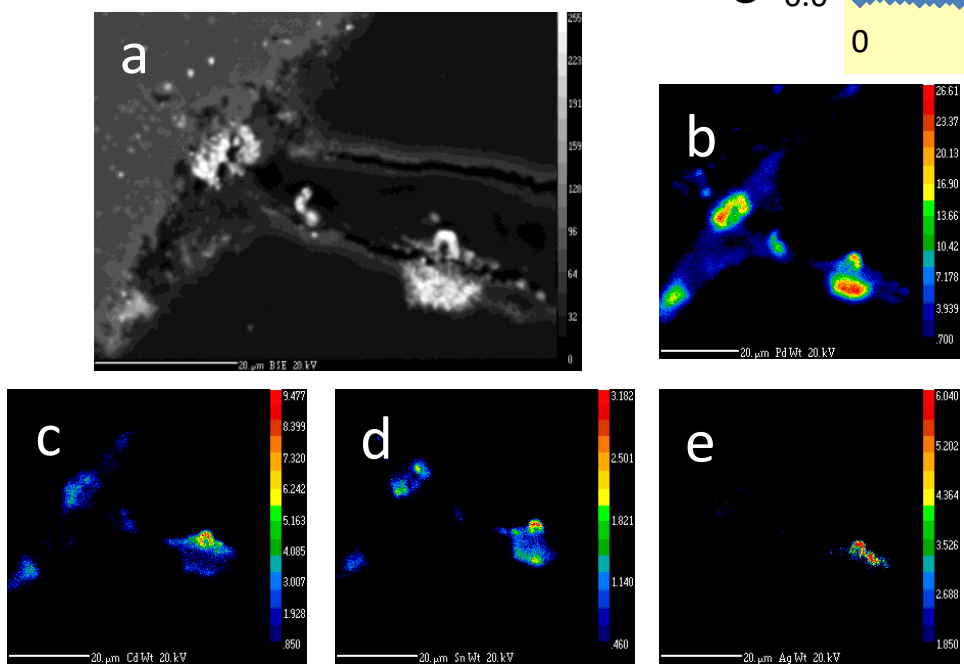

Figure 3. (a-e). a). secondary electron image of the cracked IPyC layer penetrating the SiC layer; b-e). Xray maps of $\mathrm{Pd}, \mathrm{Cd}, \mathrm{Sn}$ and $\mathrm{Ag}$ precipitates along the crack walls
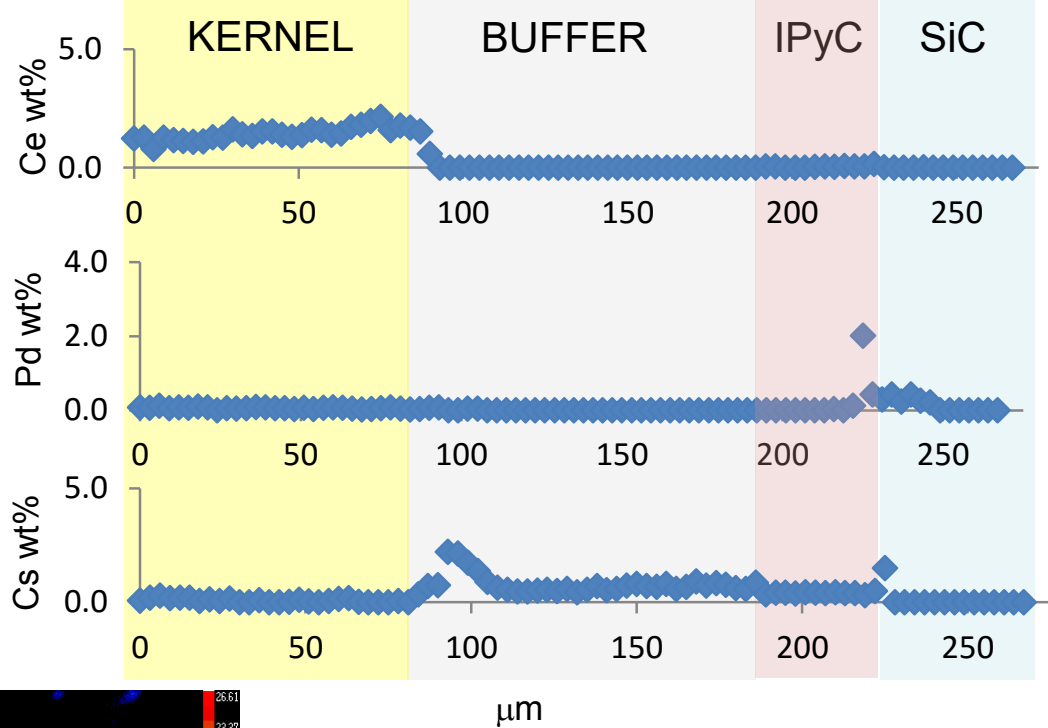

Figure 2. Examples of concentration gradients for fission products along a radial traverse 